\title{
A Influência da Opção Religiosa na Acumulação de Capital Humano: Um Estudo Exploratório
}

\author{
Francisco Anuatti-Neto \\ Renata Del Tedesco Narita
}

\author{
Professor do Departamento de Economia, \\ FEA-USP - Ribeirão Preto \\ Mestre pelo Departamento de Economia da PUC-Rio
}

\begin{abstract}
RESUMO
Esse artigo emprega estatísticas oficiais, em particular os censos demográficos de 1980 e 1991 e o questionário especial da PNAD 1988, para explorar alguns fatos estilizados da adesão religiosa no Brasil. A questão central deste trabalho é verificar se a adesão religiosa das mães afeta a acumulação de capital humano na família, independentemente de fatores socioeconômicos que poderiam explicar pelo menos parte dos efeitos observados da opção religiosa. Usou-se a escolaridade dos filhos como medida para a acumulação de capital humano. Como resultado, obteve-se que as estatísticas brasileiras reproduzem, em grande parte, os fatos estilizados de teoria econômica da religião e que podem ser observados diferenciais significativos de escolaridade entre os grupos religiosos.
\end{abstract}

\section{PALAVRAS-CHAVE}

religião, família, fecundidade, capital humano

This article explores Brazilian official statistics on religion, in particular 1980 and 199I Cen-

sus and 1988 PNAD special survey. It searches for stylized facts of economics of religion summarized in lannaccone (1998). The paper's main question is to test an empirical relation between the parents' religious affiliation and the children performance at school. This relation may indicate the existence a causal relation between religion and families' human capital accumulation. Results indicate that Brazilian data reproduces most of stylized facts and the existence of differences in children schooling among selected religious groups persist after controlling for socio-economic factors.

KEY WORDS

Religion, family structure, fertility, human capital

JEL Classification

ZI2, JI2, JI3, J24 


\section{INTRODUÇÃO}

A tendência à secularização enunciada por Max Weber na Ética Protestante previa um declínio das religiôes tradicionais como consequêencia do avanço da ciência e tecnologia, que tornaria os indivíduos cada vez mais céticos à medida que se tornassem mais educados e familiarizados com o raciocínio científico. A secularização traria uma contraposição entre a acumulação de capital humano e a adesão religiosa. Esta tese, já questionada no âmbito da própria sociologia (MACHADO, 1996), vem sendo investigada por um grupo de economistas que defende o emprego da teoria econômica para explicar o comportamento da adesão religiosa. (IANNACCONE, 1998; WARNER, 1993). As evidências empíricas, encontradas em inúmeros dados históricos dos censos norte-americanos sobre o comportamento religioso, têm permitido equacionar um conjunto de fatos estilizados que se contrapõem ao previsto pela tese da secularização. Verifica-se que a adesão religiosa nos Estados Unidos aumentou de $17 \%$ da população, na época da Independência norte-americana, para $34 \%$, na metade do século XIX, e pouco mais de 60\%, em 1998. (IANNACCONE, 1998).

Finke e Iannaccone (1993) mostram uma tendência de ramificação das instituiçôes religiosas tradicionais com o surgimento e crescimento de novas denominações religiosas, criando o que se pode chamar de mercado das religiôes. Nesse mercado as instituiçôes competem pelos fiéis ofertando serviços religiosos, como cultos, atividades comunitárias etc. Essa concorrência se dá principalmente por meio da criação de novas instituições que buscam nichos não atendidos pelas religiôes tradicionais, resultando num aumento do número de seitas e da pluralidade de religiões. É a diferenciação religiosa que permitiria a manutenção e, até mesmo, o crescimento da adesão religiosa. Empiricamente, o crescimento dessas instituições seria avaliado tanto em termos das contribuiçôes em dinheiro como no aumento da participação de adeptos na comunidade. (YOUNG, 1997; IANNACCONE, 1998).

O que constitui um motivo inerente da atividade religiosa é alguma forma de busca individual de transcendência ou da "salvação" da alma. Essa motivação, associada às pressões sociais, leva $\mathrm{o}$ indivíduo a expressar sua demanda por participação em atividades religiosas. A dimensão da demanda foi 
investigada por Ehrenberg (1975), que avaliou como uma participação religiosa ativa aumenta a probabilidade de sucesso do indivíduo no trabalho ou na aceitação por parte de grupos. As convenções sociais dão origem a motivações ligadas à aparência que um indivíduo tem de outras pessoas do mesmo grupo social ou do grupo social hegemônico em determinadas regiões. Isso implica a associação entre instituições religiosas e grupos sociais que sofrem influências da cultura, muitas vezes ligadas à cor, raça ou etnia. Assim, muito do que se associa à religião pode refletir o perfil socioeconômico do grupo a que pertence o indivíduo. As diferenças de origem étnica e social dos grupos religiosos foram abordadas por Featherman (1971), que conclui ser a escolaridade a variável mais importante para explicar os diferenciais socioeconômicos entre os grupos religiosos, mesmo depois de controladas as origens étnica e cultural destes.

Uma vez que os diferenciais socioeconômicos são fortemente explicados pela escolaridade dos indivíduos, será que a adesão religiosa dos pais influencia a escolaridade dos filhos? Se constatado este efeito, será que ele permanece mesmo depois de controlado por outros fatores socioeconômicos da família? Esse artigo tem como objetivo central explorar empiricamente o efeito da adesão religiosa das mães sobre a escolaridade dos filhos, buscando captar os efeitos da adesão religiosa na acumulação de capital humano familiar.

O artigo está divido em três seções, além dessa introdução. A primeira seção explora alguns fatos estilizados da adesão religiosa no Brasil, empregando dados das estatísticas oficiais. Para isso, são utilizados os censos demográficos de 1980 e 1991 e o questionário especial da PNAD 1988. A segunda seção aborda a questão central deste trabalho, em que são identificadas as variáveis empregadas e descrito o modelo empírico utilizado nas estimativas do impacto da adesão religiosa das mães sobre a escolaridade dos filhos. A última seção discute os resultados do estudo. 


\section{FATOS ESTILIZADOS DA ADESÃO RELIGIOSA NO BRASIL}

Qualquer estudo sobre religiões, no Brasil, deve ter como referência o crescimento explosivo das novas instituições pentecostais durante os anos 80 e a competição aberta, principalmente nos anos 90 , pelo movimento católico chamado de renovação carismática. Os novos dados do Censo 2000 permitirão, em futuro próximo, avaliar melhor os resultados dessa efervescência religiosa dos anos 90 no Brasil. Neste trabalho nos limitamos a discutir as mudanças na estrutura de participação relativa nas religiões ocorridas na década de 80, com o auxílio dos censos demográficos de 1980 e 1991 e do suplemento da PNAD (Pesquisa Nacional por Amostras de Domicílios) de 1988, do IBGE.

A Tabela 1 apresenta a comparação da adesão religiosa para o total da população brasileira em 1980 e 1991. A terceira coluna mostra as variações porcentuais no período, revelando que um maior crescimento relativo ocorreu para aqueles que declararam não possuir religião, com um aumento absoluto de aproximadamente 5 milhões de pessoas. Os católicos tiveram um crescimento inferior à taxa de crescimento populacional, mas ainda assim contaram com maior acréscimo, em número de adeptos, de aproximadamente 16 milhões entre 1980 e 1991. Por fim, há que se destacar o crescimento de $112 \%$ para as protestantes pentecostais, que apresentaram de aumento 4,3 milhões de adeptos, e dos Kardecistas, com crescimento de $91 \%$.

A explicação para esse crescimento deve ser buscada nas inovações oferecidas pelas novas denominações, isto é, devem existir fatores que afetam a oferta de serviços religiosos. As pesquisas empíricas realizadas nos censos americanos utilizam como uma aproximação para a oferta de serviços religiosos a quantidade de sacerdotes atuando em cada instituição religiosa. Para os Estados Unidos, o número de sacerdotes para cada 10.000 habitantes tem se mantido estável em torno de 12 desde 1840, subindo, na última década, para 14 sacerdotes a cada 10.000 habitantes. (IANNACCONE, 1998). 
TABELA 1 - OPÇÃO RELIGIOSA NO BRASIL ENTRE 1980 E 1991*

\begin{tabular}{|c|c|c|c|c|}
\hline Opção Religiosa & $\begin{array}{c}1980 \\
\text { (pessoas) }\end{array}$ & $\begin{array}{c}1991 \\
\text { (pessoas) }\end{array}$ & $\begin{array}{c}\text { Variação absoluta } \\
\text { 1980-1991 } \\
\text { (pessoas) }\end{array}$ & $\begin{array}{c}\text { Variação } \\
\text { porcentual } \\
\text { 1980-1991 }\end{array}$ \\
\hline Sem religião & 1.953 .096 & 6.946 .237 & 4.993 .141 & 256 \\
\hline Católicos & 105.861 .113 & 122.366 .680 & 16.505 .567 & 16 \\
\hline Prot. tradicionais & 4.022 .343 & 4.388 .311 & 365.968 & 9 \\
\hline Prot. pentecostais & 3.863 .503 & 8.179 .665 & 4.316 .162 & 112 \\
\hline Kardecistas & 859.516 & 1.644 .344 & 784.828 & 91 \\
\hline Afro-brasileiras ${ }^{\star *}$ & 678.714 & 648.475 & -30.239 & -4 \\
\hline Orientais & 257.006 & 368.579 & 111.573 & 43 \\
\hline Judaica & 91.795 & 86.422 & -5.373 & -6 \\
\hline Outras ${ }^{\star \star \star}$ & 1.124 .280 & 1.678 .952 & 554.672 & 49 \\
\hline Ignorado & 299.686 & 508.116 & 208.430 & 70 \\
\hline Total de adeptos & 117.057 .956 & 139.869 .545 & 22.811 .589 & 19 \\
\hline População & 119.011 .052 & 146.815 .782 & 27.804 .730 & 23 \\
\hline
\end{tabular}

No Brasil, um levantamento dessas informações permitiu constatar um aumento no número absoluto de sacerdotes de 31.477, em 1980, para 36.281 , em 1991. Esse crescimento, em torno de 15\%, foi inferior ao crescimento populacional, havendo, de fato, uma pequena queda de 2,64 sacerdotes para cada 10.000 habitantes em 1980, para 2,47 em 1991. Os dados médios não revelam o que de fato estava ocorrendo com os indicadores por religião no período. Quando se identifica a denominação religiosa dos sacerdotes constata-se que o número de sacerdotes católicos praticamente não se alterou, 16.319 em 1980 e 16.343 em 1991, resultando num índice de 1,5 sacerdote para cada 10.000 católicos. Já as protestantes tradicionais apresentam o mais elevado índice: em torno de 18 sacerdotes para cada 10.000 adeptos, com um número absoluto estável, variando apenas de $7.321 \mathrm{em}$ 1980, para 7.650 em 1991. 
A grande elevação do número de sacerdotes ocorreu entre as pentecostais, crescendo de 4.755 em 1980, para 9.159 em 1991, mantendo um índice estável, em torno de 12 sacerdotes por 10.000 adeptos ao pentecostalismo. $\mathrm{O}$ aumento do número de sacerdotes pentecostais lembra o fato de que não só a quantidade de seguidores cresceu, mas também a criação de novas igrejas pentecostais ocorreu por conta deste aumento. Um levantamento feito pelo ISER (Instituto Superior de Estudos da Religião) acrescenta que durante os três primeiros anos da década de 90, 91,27\% dos novos templos criados eram pentecostais. (MACHADO, 1996). Nota-se, portanto, que enquanto os indicadores para as igrejas protestantes aproximam-se daqueles encontrados para os Estados Unidos, o número de sacerdotes católicos por adeptos é bastante inferior. $^{1}$

A participação em atividades religiosas demanda pelo menos dois tipos de recursos materiais, recursos financeiros e tempo dedicado aos cultos e outras atividades sociais e comunitárias. Nesse sentido, modelos de alocação de tempo podem ser empregados para determinar alguns fatos estilizados da participação religiosa. Azzi e Ehrenberg (1975) e Ehrenberg (1977) encontram evidências empíricas entre características pessoais e adesão religiosa. Essas correlações podem ser tratadas como fatos estilizados que procuraremos verificar para o Brasil.

Por exemplo, foi encontrado que mulheres tendem a participar mais de atividades ligadas à instituição religiosa do que homens. Ehrenberg (1977) aponta como causa provável o fato de as mulheres terem custo de oportunidade menor que o de homens na alocação de tempo para a atividade religiosa. Além disso, esse custo de oportunidade é ainda maior para mulheres com filhos em idade escolar. Outro fato estilizado verificado é a participação crescente com a idade, apresentando um declínio inicial até a faixa de 30 a 35 anos e outro que ocorre a partir dos 60 anos, o que pode ser atribuído ao estado de saúde destes. A relação entre renda e participação nas atividades religiosas é positiva, mas não é claro se o efeito se mantém para os níveis mais elevados de renda. Além disso, para os Estados Unidos, constatou-se

1 A reação da Renovação Carismática nos anos 90 é claramente baseada num forte apelo aos meios de comunicação de massa, na realização de grandes eventos e em padres 'estrelas', o que pode ser um meio para compensar a distância entre sacerdote e fiel. 
que a freqüência dos negros é maior que a dos brancos e que a participação religiosa nas áreas rurais é maior que em áreas urbanas.

A melhor, e talvez única, fonte de informações para explorar esses fatos estilizados no Brasil encontra-se no suplemento especial da PNAD 1988, do IBGE, pois permite avaliar o grau de adesão religiosa, medido pela freqüência, e o relacionamento deste com as variáveis socioeconômicas. ${ }^{2}$ Infelizmente, o suplemento não adotou as mesmas denominações religiosas presentes no Censo, agregando-as em 5 grandes grupos: católicas, protestantes, kardecistas, afro-brasileiras (candomblé e umbanda) e outras. Perdeu-se, assim, a possibilidade de explorar as diferenças entre protestantes tradicionais e pentecostais.

O primeiro fato estilizado é a participação relativa de homens e mulheres. Pode-se verificar a freqüência da participação religiosa por meio de quatro categorias, quais sejam: semanal, mensal, anual ou não freqüenta. Como mostra a Figura 1, um maior porcentual de freqüência semanal na atividade religiosa é encontrado entre as mulheres (35\%), enquanto para os homens é de $25 \%$.

FIGURA 1 - PARTICIPAÇÃO DE MULHERES E HOMENS - BRASIL, PNAD 1988

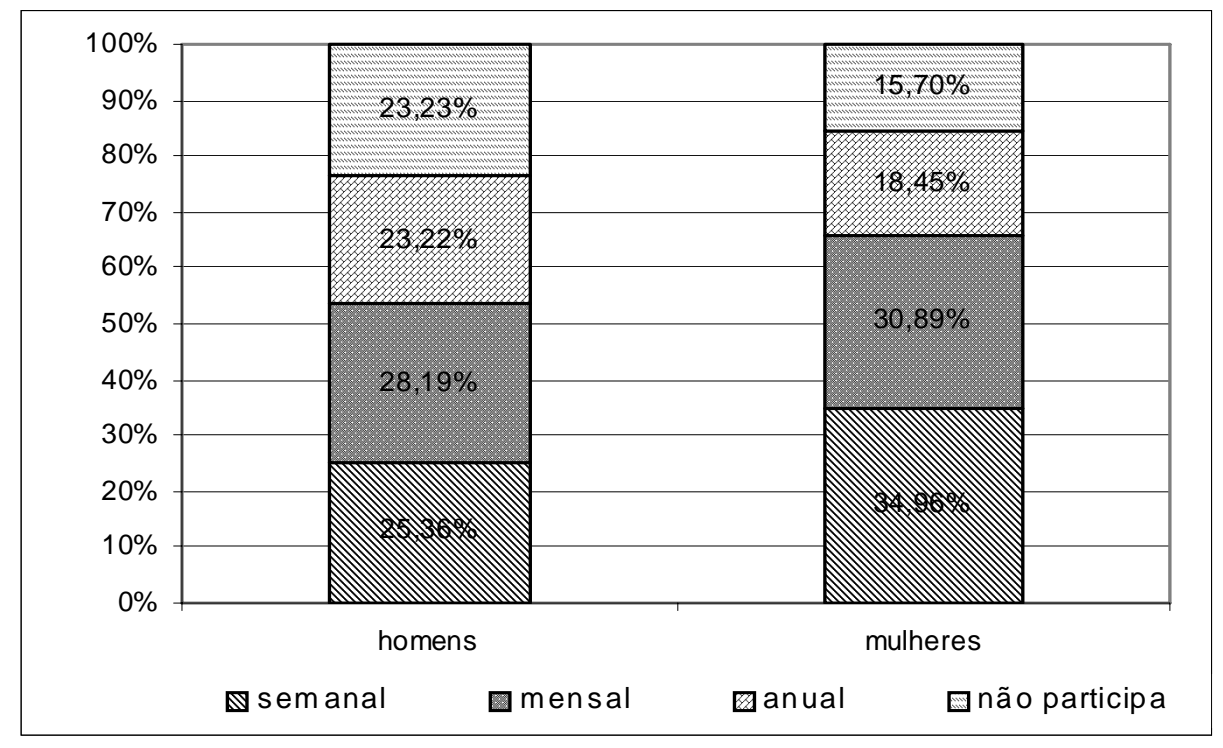

2 A freqüência da adesão foi classificada pelo IBGE em semanal, mensal, anual e, inclusive, aqueles que apesar de declararem ter uma opção religiosa, não participavam dos cultos. 
O segundo fato estilizado (Figuras 2 e 3 ) é que mulheres com filhos em idade escolar tendem a ser menos freqüentes nas atividades religiosas. Na Figura 2, observa-se uma menor freqüência semanal das mulheres com filhos menores de 7 anos em relação às demais. Já na Figura 3, nota-se que a participação semanal se eleva com a presença de filhos em idade escolar, confirmando a hipótese de que a adesão religiosa pode refletir um problema de alocação de tempo das mulheres, que devem destinar parte de seu tempo na dedicação aos filhos, principalmente na fase em que eles ainda não estão na escola.

FIGURA 2 - FREQÜÊNCIA DA ADESÃO RELIGIOSA CONFORME A PRESENÇA DE FILHOS EM IDADE PRÉ-ESCOLAR (MENORES DE 7 ANOS) - BRASIL, PNAD 1988

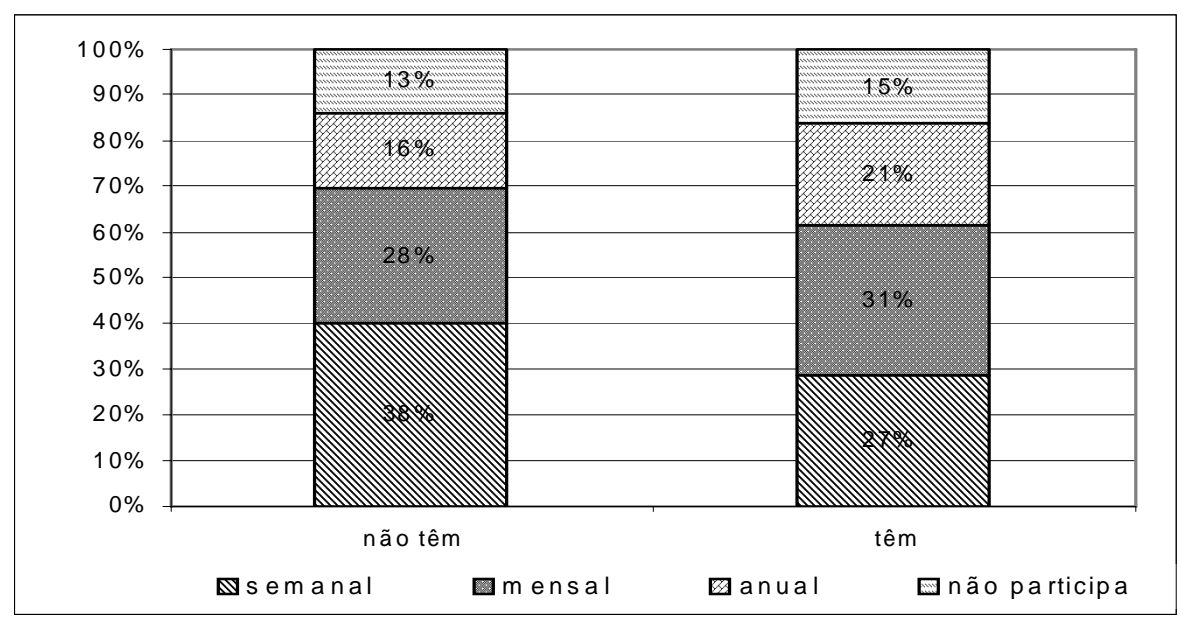

FIGURA 3 - FREQÜENCIA DA ADESÃO RELIGIOSA CONFORME A PRESENÇA DE FILHOS EM IDADE ESCOLAR (MAIOR OU IGUAL A 7 ANOS) - BRASIL, PNAD 1988

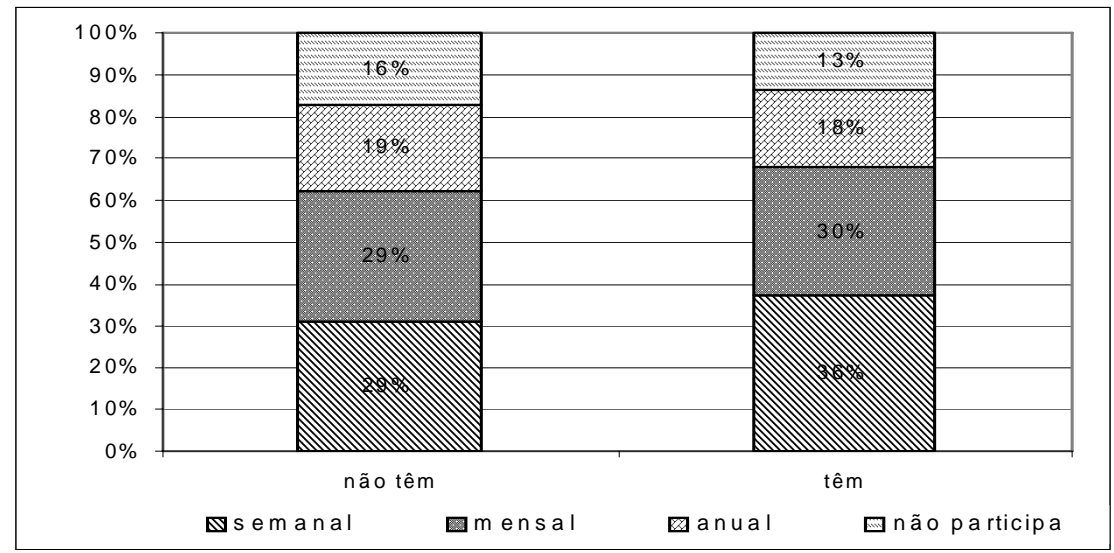

Est. econ., São Paulo, 34(3): 453-486, jul-set 2004 
O terceiro fato estilizado é a relação positiva entre renda e participação religiosa, observado na Figura 4. Pode-se notar que a participação religiosa cresce conforme aumenta a renda familiar per capita até o terceiro quartil, e para o último quartil tem-se uma tendência de queda da freqüência semanal. A adesão aumenta com a renda, pois reduz o custo de oportunidade do tempo na atividade religiosa, resultado verificado nos níveis mais baixos de renda. Assim como obtido em Ehrenberg (1977), o resultado ambíguo para os níveis de renda mais altos leva a concluir que o aumento da renda não define uma relação estável de crescimento da freqüência da adesão religiosa.

FIGURA 4 - FREQÜÊNCIA DA ADESÃO RELIGIOSA POR RENDA FAMILIAR PER CAPITA - BRASIL, PNAD 1988

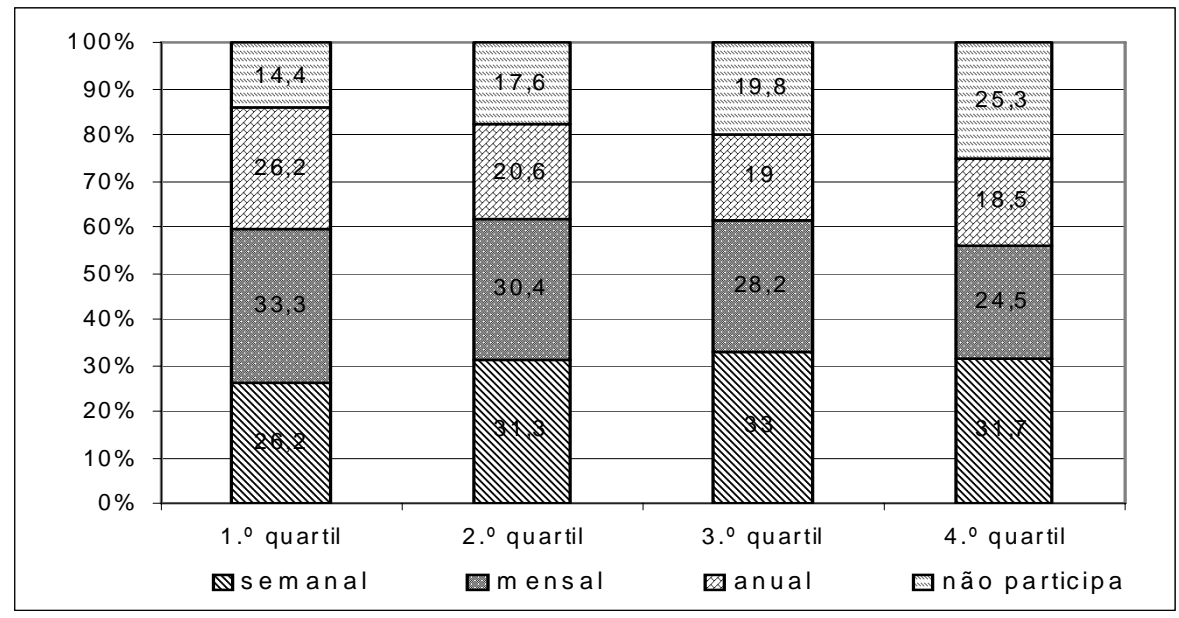

O quarto fato estilizado apontado por Azzi e Ehrenberg (1975) é reproduzido na Figura 5: a participação religiosa por cor no Brasil diverge daquela encontrada nos EUA. Aqui os brancos participam mais (freqüência semanal) do que negros, pardos e pessoas de cor amarela. Esses resultados devem-se ao elevado porcentual de negros e pardos que declaram possuir religião mas não são praticantes. 
FIGURA 5 - FREQÜENCIA DA ADESÃO RELIGIOSA POR COR/RAÇA BRASIL, PNAD 1988

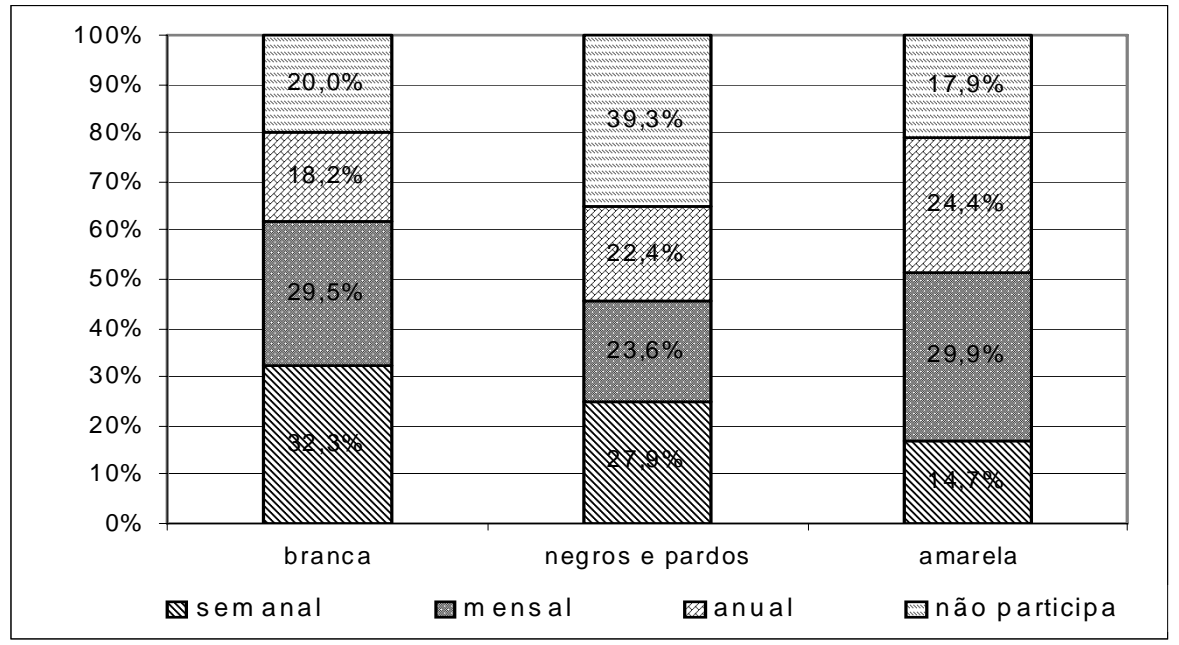

Na Figura 6 procura-se melhorar o controle para as comparações entre cores considerando-se apenas os indivíduos com freqüência semanal e para cada quartil de renda familiar per capita. Neste caso, a adesão de negros e pardos passa a ser superior à verificada para os indivíduos de cor amarela, aproximando-se, inclusive, do que foi encontrado para brancos no quartil superior da renda, o que mostra que o grau de adesão aumenta conforme a renda para brancos, negros e pardos e reduz para pessoas de cor amarela.

\section{FIGURA 6 - FREQÜENNCIA SEMANAL DA ADESÃO RELIGIOSA POR COR/ RAÇA CONFORME RENDA FAMILIAR PER CAPITA - BRA- SIL, PNAD 1988}

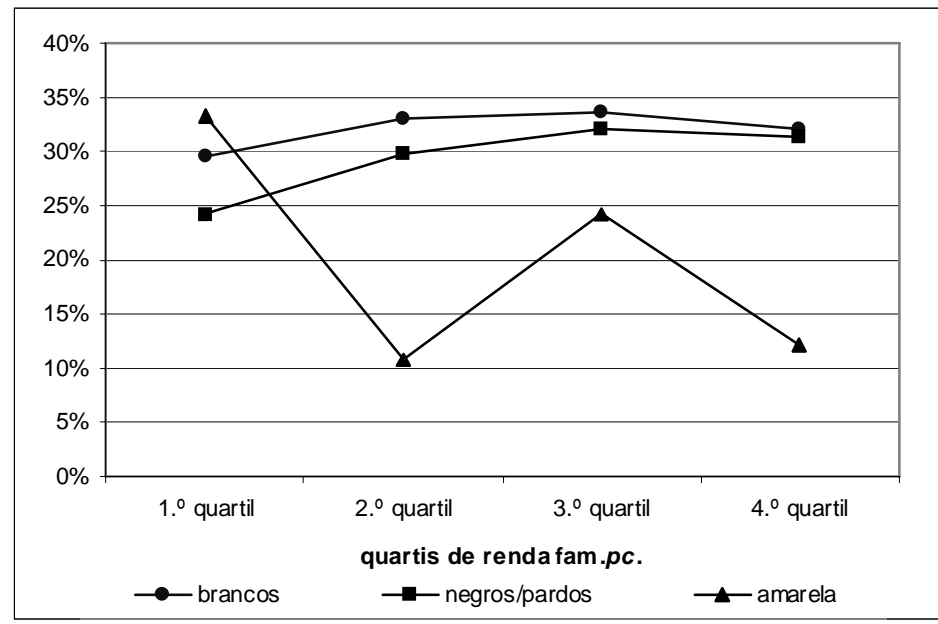

Est. econ., São Paulo, 34(3): 453-486, jul-set 2004 
O quinto fato estilizado é a diferença entre a participação religiosa entre áreas rurais e urbanas. A Figura 7 apresenta a distribuição de participação dos indivíduos residentes em área rural e urbana, e mostra que os residentes em áreas rurais possuem menor participação semanal (32\% dos adeptos) do que os residentes em área urbana (24\%). Somando as freqüências semanal e mensal, os residentes em área rural superam os urbanos em pouco mais de $2 \%$.

FIGURA 7 - FREQÜÊNCIA DA ADESÃO RELIGIOSA POR ÁREA GEOGRÁFICA - BRASIL, PNAD 1988

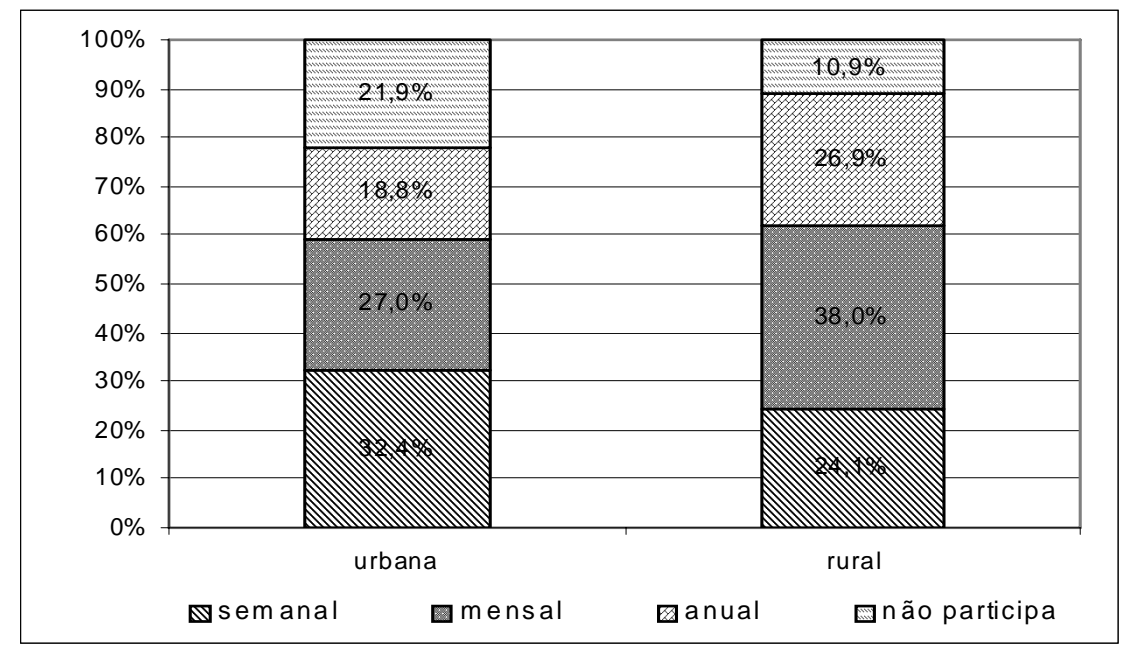

O resultado, para o Brasil, não reproduz o encontrado para o caso americano. Esta divergência permanece mesmo quando são controlados os efeitos da renda. Para interpretar melhor este fato, a Figura 8 apresenta as freqüências de participação semanal para os residentes em área rural e urbana para cada quartil de renda familiar. As freqüências rurais são inferiores às dos residentes urbanos nos três primeiros quartis e apenas se aproximam para níveis mais elevados de renda. Provavelmente, a existência de diferenças nos custos de transação e na oferta de serviços religiosos para a população rural brasileira podem estar revelando uma demanda reprimida por participação religiosa no meio rural. 
FIGURA 8 - FREQÜÊNCIA SEMANAL DA ADESÃO RELIGIOSA POR ÁREA GEOGRÁFICA CONFORME RENDA FAMILIAR PER CAPITA - BRASIL, PNAD 1988

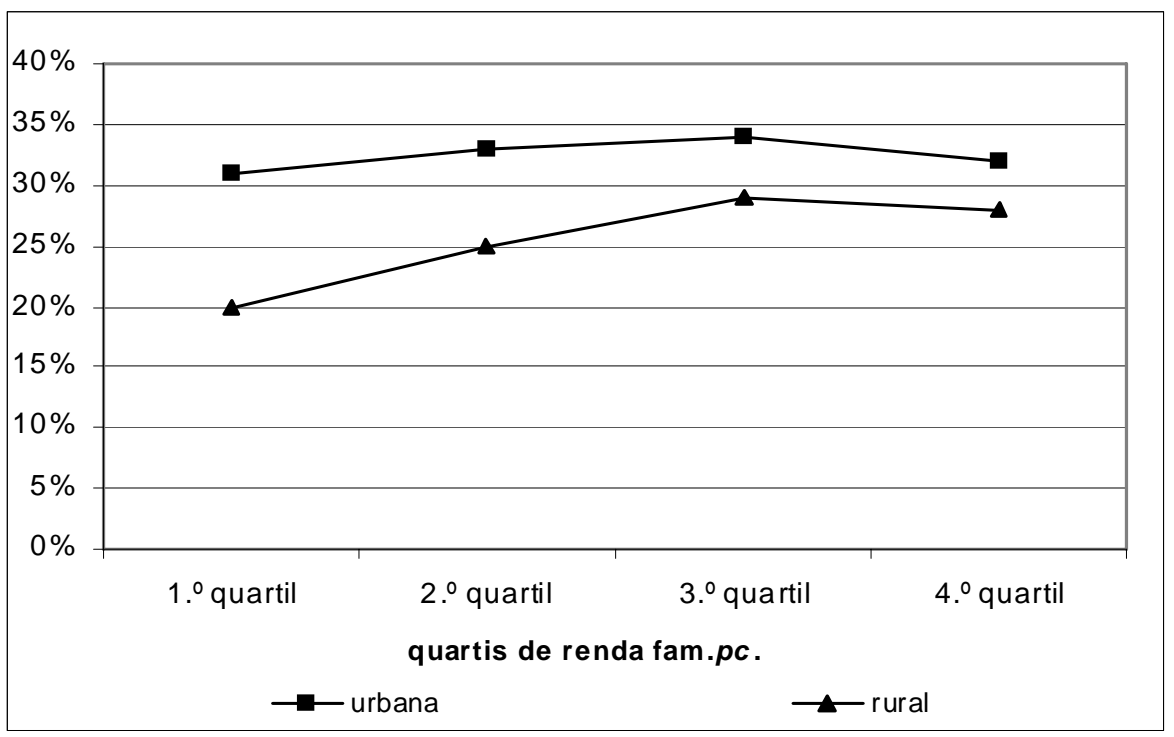

O sexto e último fato estilizado a ser avaliado é o diferencial de participação religiosa por idade. Neste caso, a Figura 9 apresenta resultado semelhante ao encontrado no caso americano. Verifica-se uma queda na freqüência semanal para pessoas com idade entre 18 e 34 anos e um crescimento a partir da faixa dos 35 aos 39 anos. A tendência de crescimento permanece até os 80 anos quando, a partir daí, ocorre uma rápida elevação do porcentual de não praticantes. Verificando essa tendência por sexo, identifica-se uma sensível queda inicial da participação das mulheres da faixa de 18 a 23 anos, enquanto os homens teriam uma queda mais acentuada de 18 até meados de 40 anos. Essa queda inicial prolongada da adesão religiosa dos homens, identificada pelo declínio até 40 anos, pode refletir um elevado custo de oportunidade da alocação de tempo para a atividade religiosa, sendo que ainda nesta fase as possibilidades de ganhos no mercado de trabalho são maiores. ${ }^{3}$ Por-

3 Estimando-se, com os dados da PNAD 1988, uma equação de salários padronizados por horas de trabalho $(\log )$ conforme as explicativas escolaridade, sexo, área geográfica, idade e quadrado da idade, nota-se que os salários aumentam com a idade até os 49 anos, e depois apresentam tendência declinante. 
tanto, o custo de adesão torna-se, a partir daí, menor, elevando a participação em termos semanais.

FIGURA 9 - FREQÜENNCIA SEMANAL DA ADESÃO RELIGIOSA POR IDADE - BRASIL, PNAD 1988

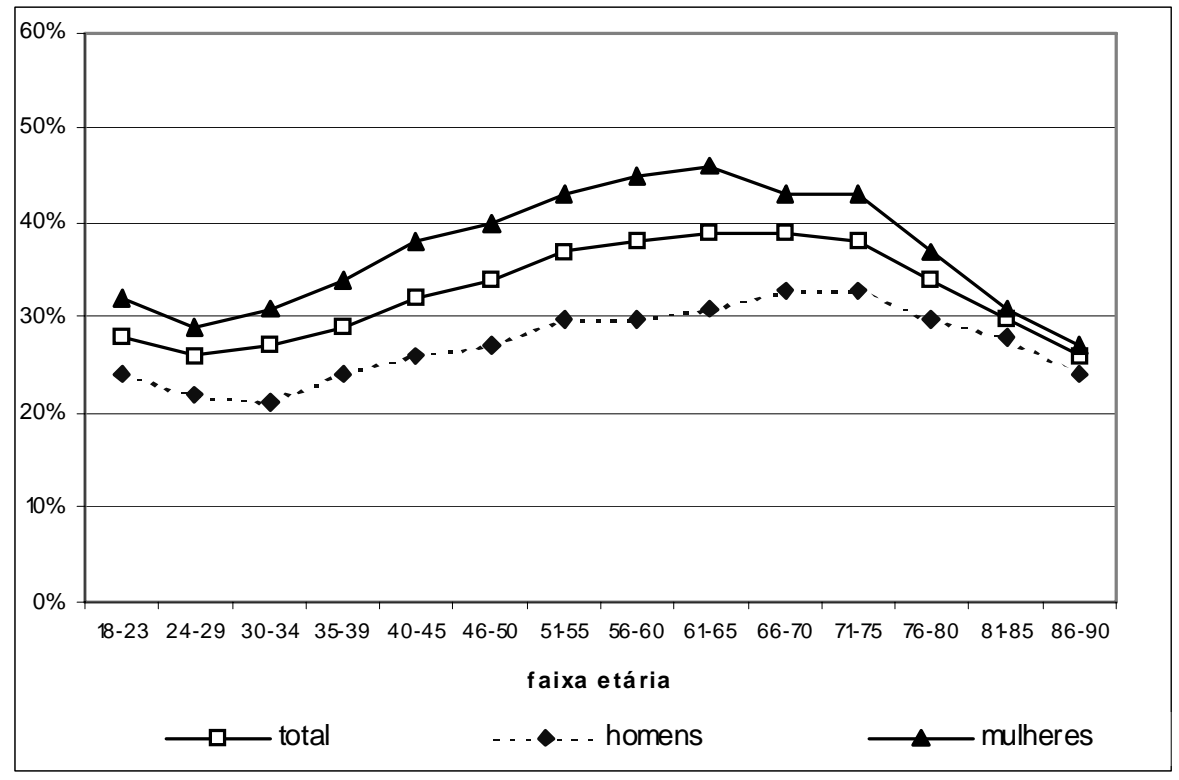

Além disso, mulheres tendem a participar mais das atividades ligada à religião do que os homens, assim como a presença de filhos com menos de 7 anos tende a reduzir a participação religiosa. A mesma tendência foi verificada com relação à adesão por idade e conforme a renda familiar per capita.

Uma característica típica da sociedade brasileira é o chamado sincretismo religioso. Este fenômeno social tem como principal evidência a participação em mais de uma instituição religiosa. Existem informações no suplemento da PNAD de 1988 que permitem avaliar a extensão e as características desse comportamento. Em geral, pode ser observado um alto grau de coerência dos fiéis em suas opções, ou seja, 94,6\% declararam possuir apenas uma única opção religiosa. As protestantes foram as que apresentaram um porcentual mais elevado $(96,58 \%$ do total). Em seguida, as católicas apresentaram um número não muito inferior às protestantes, ou seja, 94,64\% dos católicos participavam exclusivamente nesta instituição. As instituições me- 
diúnicas - kardecistas e afro-brasileiras - foram as que mostraram um menor grau de coerência da opção religiosa. A Tabela 2 indica que 11,9\% dos espíritas kardecistas e 16,6\% dos seguidores de religiões afro-brasileiras possuem o catolicismo como segunda religião. Isto provavelmente tenha ocorrido pela estrutura destas próprias instituições, que não deve proibir a participação dos seus seguidores em outros cultos e também pelo fato de instituições como a kardecista apresentarem uma adesão crescente, como foi visto na Tabela 1 , podendo estar recebendo adeptos do catolicismo, instituição esta que apresentou crescimento inferior ao populacional.

TABELA 2 - OPÇÃO RELIGIOSA E PARTICIPAÇÃO EM OUTRAS RELIGIÕES - BRASIL, 1988*

\begin{tabular}{lrrrrrrr}
\hline Opção & \multicolumn{7}{c}{ Outra religião que participa (\%) } \\
\cline { 2 - 8 } Religiosa & Nenhuma & Católica & Protestante & Kardecista & $\begin{array}{c}\text { Afro- } \\
\text { Brasileiras }\end{array}$ & Outras & Total \\
\hline Católica & 94,64 & - & 2,74 & 1,58 & 0,80 & 0,24 & 100 \\
Protestantes & 96,58 & 2,81 & - & 0,33 & 0,04 & 0,22 & 100 \\
Kardecistas & 85,95 & 11,92 & 1,12 & - & 0,38 & 0,64 & 100 \\
Afro-brasileiras & 81,72 & 16,58 & 0,79 & 0,70 & - & 0,21 & 100 \\
\hline
\end{tabular}

* PNAD 1988, IBGE. **Candomblé, Umbanda.

Conclui-se que há um elevado grau de coerência dos indivíduos em suas opções religiosas e levanta-se o possível aspecto de transição para as kardecistas, que receberam muitos fiéis nos anos 80 . A variável religião foi construída pelo IBGE com base na religião declarada pelo entrevistado. Entretanto, nem sempre o indivíduo que diz ser seguidor de uma determinada religião participa dos cultos desta. Para isto, incluiu-se a variável frequiência de participação, específica da PNAD 1988, que constitui uma medida aproximada para o grau de adesão à instituição religiosa.

Os resultados encontrados na Tabela 3 mostram que para o total de indivíduos que possuem religião somente $30,33 \%$ freqüentam semanalmente os cultos, enquanto 29,68\% possuem freqüência mensal, 20,74\% anual e $19,23 \%$ não participam dos cultos. Estes números incorporam, em grande parte, os números apresentados pelos católicos, que constituem a maioria da 
população religiosa do País. Apenas 24,93\% dos católicos freqüentam a instituição semanalmente, sendo também expressivo o porcentual destes que não participam dos cultos $(20,89 \%)$.

Por outro lado, as estatísticas das outras religióes mostraram, em grande parte, um elevado grau de adesão dos seus seguidores. A instituições protestantes, representadas aqui tanto pelas evangélicas tradicionais quanto pelas pentecostais, possuem $70,81 \%$ de fiéis com freqüência semanal e 16,81\% com freqüência mensal, somando-se $87,62 \%$ do total de evangélicos. Em seguida, as religióes afro-brasileiras possuem $82,33 \%$ dos seus seguidores que freqüentam semanal e mensalmente as instituições.

TABELA 3 - GRAU DE PARTICIPAÇÃO DOS FIÉIS POR INSTITUIÇÃO RELIGIOSA (\%) - BRASIL, 1988*

\begin{tabular}{lrrrccc}
\hline Opção Religiosa & Semanal & Mensal & Anual & Não participa & Sem declaração & Total \\
\hline Católica & 24,93 & 31,27 & 22,89 & 20,89 & 0,02 & 86,61 \\
Protestantes & 70,81 & 16,81 & 5,45 & 6,91 & 0,01 & 10,24 \\
Kardecistas & 53,92 & 23,97 & 8,71 & 13,40 & - & 1,98 \\
Afro-brasileiras & 42,09 & 40,24 & 8,87 & 8,15 & 0,64 & 0,54 \\
Outras & 43,07 & 17,73 & 16,89 & 22,26 & 0,05 & 0,63 \\
\hline Total & 30,41 & 29,61 & 20,71 & 19,25 & 0,02 & 100 \\
\hline
\end{tabular}

* PNAD 1988, do IBGE. **Candomblé, Umbanda.

Pôde ser observado que apesar de a instituição católica ter apresentado um aumento na quantidade de adeptos de 1980 a 1991, encontrou-se um grau de adesão inferior ao das demais religiões analisadas, principalmente em relação às protestantes e kardecistas. 


\section{ACUMULAÇÃO DE CAPITAL HUMANO NA FAMÍLIA: A IN- FLUENNCIA DA OPÇÃO RELIGIOSA DAS MÃES}

Uma característica importante associada às religiões é a capacidade que elas têm de influenciar o comportamento dos fiéis com relação ao matrimônio e à decisão de ter filhos. Estes efeitos criam um elo entre família e religião. Algumas religiões têm o interesse de influenciar as decisões familiares, pois é por meio da família que estas podem difundir-se em maior escala, atingindo várias gerações e perpetuando os valores e rituais religiosos. Uma importante implicação econômica do estudo da religião é identificar a relação desta com o comportamento familiar, principalmente quando se trata da escolha do número de filhos e do investimento na qualidade de vida ou bem-estar destes.

O censo demográfico de 1991 permite descrever a relação entre opção religiosa, escolaridade e números de filhos para as mulheres brasileiras entre 40 a 45 anos. $^{4}$ A relação entre fecundidade e opção religiosa, sem qualquer controle de escolaridade, é apresentada na coluna mais escura ao centro na Figura 10, apresentado em ordem decrescente de fecundidade. As mulheres das instituições pentecostais têm, em média, 4,96 filhos, e no outro extremo as mulheres judia têm 2,33 filhos. Uma vez controlados por grupos de escolaridade, pôde-se identificar que para todas as denominações as mulheres com maior nível de escolaridade tiveram a fecundidade reduzida, o inverso sendo válido para as de menor escolaridade. Entre as de maior escolaridade, as taxas encontradas estão mais concentradas (em torno de 2), sugerindo

que as diferentes taxas de fecundidade refletem, em boa parte, as diferenças de escolaridade das adeptas. ${ }^{5}$

4 A escolha dessa faixa etária, 40 a 45 anos, deve-se ao fato deste grupo de mulheres apresentar maior estabilidade quanto ao número de filhos, e também deve apresentar maior estabilidade no que se refere à opção religiosa declarada.

5 Foi testada a hipótese de que a fecundidade média era igual entre as diferentes opções religiosas. Em um nível de significância de $5 \%$ rejeitou-se a hipótese testada, mesmo quando realizado o controle pela escolaridade dos adeptos, o que mostra que a taxa de fecundidade difere estatisticamente entre as opções religiosas. 
FIGURA 10 - TAXAS DE FECUNDIDADE E ESCOLARIDADE DAS MULHERES DE 40 A 50 ANOS CONFORME A OPÇÃO RELIGIOSA - BRASIL, CENSO 1991

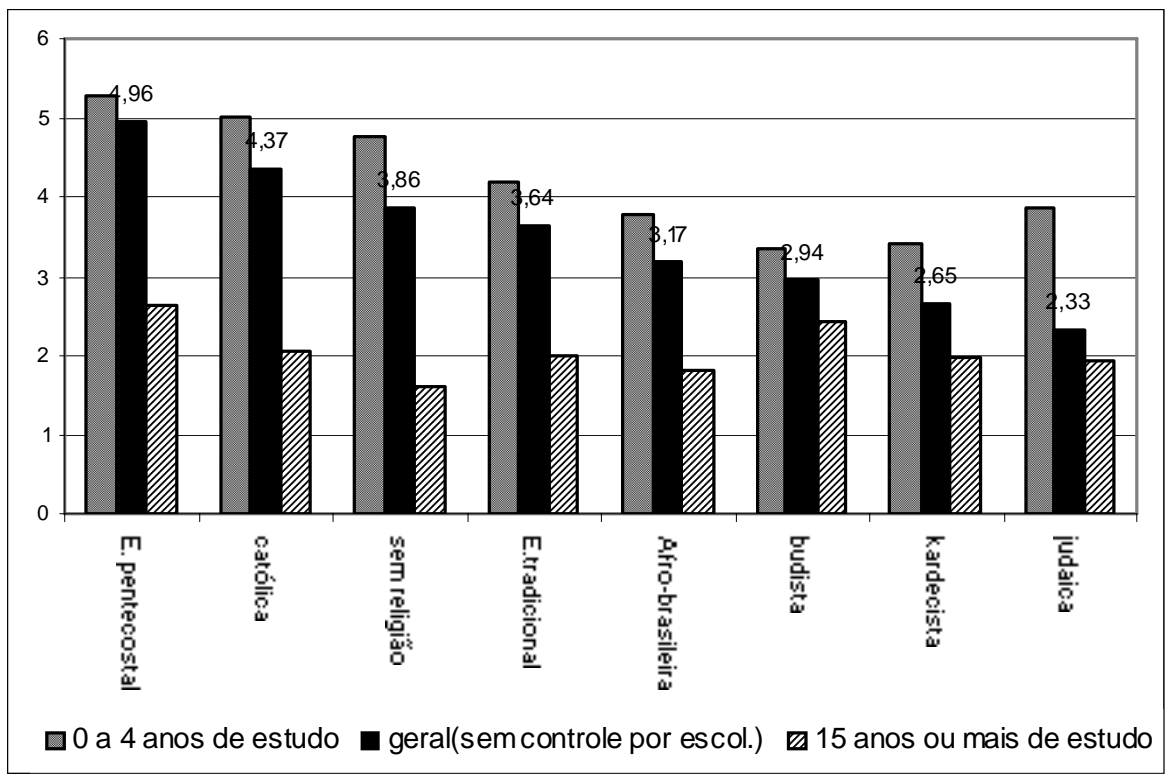

Leibowitz (1974), seguindo Ben-Porath (1967), desenvolveu um modelo em que a acumulação de capital humano familiar ocorre por meio de dois mecanismos de transmissão das características dos pais para o desempenho escolar dos filhos. O primeiro mecanismo é o da transmissão das características hereditárias, como inteligência (Q.I.), e o segundo é a qualidade e quantidade de tempo e de recursos financeiros alocados na educação dos filhos. Este último é o investimento familiar total, que possui efeito direto sobre a escolaridade dos filhos ou, de forma indireta, influenciando a constituição de suas habilidades inerentes (Q.I.). Para o autor, a escolaridade dos pais é uma medida importante para se avaliar a qualidade do tempo gasto no cuidado com os filhos e também pode agir como uma proxy para as características hereditárias, se a inteligência dos pais estiver positivamente correlacionada com a própria escolaridade. O nível de capital humano inicial reflete a habilidade inerente ao indivíduo, que permite alcançar níveis diferenciados de competência tanto verbal quanto aquela voltada ao desenvolvimento do raciocínio lógico, mas também inclui a educação obtida na família, principalmente na fase que precede a entrada do indivíduo na esco- 
la. O estoque de capital humano adquirido reflete, por sua vez, o nível de capital humano inicial, a educação formal obtida nas escolas e, finalmente, os investimentos familiares, via renda ou horas destinadas aos filhos. Para Leibowitz, a escolaridade das mães não só é importante para prever a formação de capital humano inerente ao indivíduo, mas também constitui uma variável proxy para o investimento familiar não financeiro na educação dos filhos, isto é, a qualidade do tempo dedicado a eles. Ao contrário, a escolaridade dos pais tem pouco efeito sobre o estoque de capital humano inerente aos filhos, mas é uma proxy para o investimento familiar em termos de alocação de renda.

Se a opção religiosa é uma parte das características dos pais, que ao serem transmitidas afetam o desempenho esperado dos filhos, é possível então que existam efeitos dessa opção religiosa sobre a acumulação de capital humano. Para Iannaccone (1998), a religião herdada seria um aporte de capital humano na função de produção familiar, pois a religião dos pais diminui o custo de aprendizagem de aderir a uma religião diferente e se inserir em outra comunidade. Os mecanismos que geram as externalidades da opção religiosa dos pais sobre os filhos podem ocorrer por meio do comportamento do indivíduo dentro do grupo, ou ainda por afetar as preferências dos pais em relação à qualidade e quantidade do tempo dedicado aos filhos e dos recursos destinados à educação. Sem a pretensão de abordar as explicações teóricas desses efeitos, discutiremos a seguir um teste empírico do impacto da opção religiosa das mães sobre a escolaridade dos filhos.

\section{II.1 A Natureza dos Dados e o Modelo Empirico}

Para a realização dos testes foi selecionada uma amostra constituída por cerca de 440.000 mulheres brasileiras, de 40 a 45 anos, que possuem filhos com idade entre 7 e 22 anos. Os dados foram obtidos do Censo Demográfico de 1991, do IBGE.

O procedimento adotado foi estimar uma equação linear de forma a permitir que as contribuições marginais da opção religiosa para a acumulação de capital humano possam ser obtidas por Mínimos Quadrados Ordinários. O modelo adotado com base em Leibowitz (1974) é apresentado abaixo: 


$$
Q_{i}=\alpha+\beta_{1} K_{i}+\beta_{2} D_{i}+\beta_{3} S_{i}+\beta_{4} Z+\mu_{i}
$$

$Q_{i}$, acumulação bruta de capital humano, medida pela escolaridade do filho mais velho;

$K_{i}$, estoque de capital humano existente, tendo como proxy a escolaridade das mães;

$D_{i}$, quantidade de insumos alocados para produção de $Q_{i}$, é a renda familiar per capita (do pai);

$S_{i}$, proporção de $K_{i}$ alocado para produção de $Q_{i}$;

$Z$, conjunto de variáveis de controle: idade e cor ou raça da mãe, dummies para macrorregiões e regiões metropolitanas, idade do filho mais velho;

$\alpha$ é o termo constante;

$\mu$ é o termo aleatório.

A hipótese de identificação primordial está relacionada a $S_{i}$. Esta proporção é uma medida não observada diretamente por meio dos dados empíricos, pois não há dados disponíveis de alocação de tempo e qualidade de tempo destinado à educação dos fillhos, bem como os censos demográficos não incluem as despesas da família com escola ou outros gastos relacionados à formação educacional dos filhos. Ao invés de características mensuráveis para a proporção do estoque de educação que os pais possam transferir aos filhos, existem outros elementos não mensuráveis que são fruto da preferência dos pais por investir na qualidade e quantidade de tempo (dedicação) e quantidade e qualidade de recursos (renda familiar) destinados aos filhos. Estes elementos não mensuráveis poderiam ser representados pelas influências religiosa e cultural, que definem um padrão de comportamento familiar diferenciado. Sendo assim, pela equação abaixo, foi considerado $S_{i}$ como função da opção religiosa das mães, estado civil dos pais e número de irmãos.

$$
S_{i}=f\left(\operatorname{Rel}_{i} S c_{i}, n_{i}\right)
$$


$R e l_{i}$ representa a opção religiosa da mãe (católica, evangélica tradicional, evangélica pentecostal, judaica, afro-brasileira, budista, kardecista, sem religião, outras);

$S c_{\text {i }}$, representa o estado civil da mãe (casada religioso/civil e religioso, união consensual/casamento civil, separada/divorciada, solteira);

$n$ é o número de irmãos.

A proporção do estoque de capital humano dos pais alocada para o investimento na acumulação de capital humano dos filhos seria determinada pela opção religiosa, estado civil dos pais, número de irmãos e pelo relacionamento destas variáveis entre si. A subseção seguinte apresenta a justificativa para a escolha das variáveis apresentadas na equação (1).

\section{II.2 Descrição das Variáveis}

A escolha da opção religiosa das mães segue, em grande parte, a contribuição de Machado (1996): "Analisar a mulher significa, de certa forma, analisar a instituição da familia já que a figura feminina tem a dupla responsabilidade da reprodução biológica e da própria reprodução social da familia, assumindo diretamente a responsabilidade pela manutenção dos filhos ou cuidando da reprodução de seus valores e crenças." Outro fato que reforça a opção pelas características das mães, ressaltada pela autora, é que a conversão dos cônjuges normalmente é consensual, e que ela é definida pelo fato de, em geral, a opção religiosa do pai ser a mesma da mãe. Outro motivo, de fundamental importância, para a escolha da opção religiosa das mães é o fato de esta ser a que mais se aproxima de uma variável exógena à escolaridade dos filhos. Esta hipótese é razoável se for admitido que a religião das mães é a religião "herdada" pelos filhos.

Em termos de alocação de tempo, existe o problema da limitação dos dados, que apenas possibilitam identificar conjuntamente as características dos membros da família caso estes morem no mesmo domicílio. Famílias desagregadas, com pais e mães vivendo em domicílios diferentes, provavelmente possuem mais filhos morando com a mãe do que com o pai. Portanto, a au- 
sência do pai no domicílio em que mãe e filhos moram juntos torna necessária a escolha das características das mães para estudar o investimento em capital humano da família.

Leibowitz (1974) testou empiricamente se a ordem de nascimento do filho afetava a sua acumulação de capital humano inicial e verificou que filhos primogênitos possuem um maior estoque de capital humano. Além disso, estudos mostram que o grau de participação religiosa aumenta com a idade da mulher, mesmo após controlado o efeito cohort. (IANNACCONE, 1998; AZZI \& EHRENBERG, 1975). A delimitação do grupo das mulheres de 40 a 45 anos deve-se ao fato de que este apresenta maior estabilidade quanto ao número de filhos, justificando a opção pela escolha do filho mais velho, onde se espera captar a máxima acumulação de capital humano na família.

Entretanto, é comum que haja um declínio inicial da adesão para mulheres entre 30 e 35 anos, pois o custo de oportunidade do tempo reservado para a participação religiosa é relativamente maior para mulheres dessa faixa etária, dado que nesse período elas podem adquirir maiores taxas de salário quando alocam mais tempo para o trabalho. (AZZI \& EHRENBERG, 1975). Acrescenta-se a isto o fato, já citado, de que a base de dados utilizada consegue identificar conjuntamente características de pais e filhos desde que estes estejam morando no mesmo domicílio. ${ }^{6}$ Reunindo todos estes elementos, é razoável supor que mulheres de 40 a 45 anos constituem o melhor grupo para se estimar a influência da adesão religiosa sobre a escolaridade dos filhos de maior idade.

A escolha da renda familiar proveniente apenas do pai apresenta o motivo que, se incluída a renda dos filhos, pode estar sendo criada uma estimativa enviesada da contribuição da renda familiar sobre a qualidade da educação destes, medida pela escolaridade, uma vez que filhos que trabalham antes de completar o ciclo educacional devem estar substituindo o estudo pelo trabalho e, assim, um incremento da renda familiar ocasionada pela incorporação

6 Calculou-se o porcentual de filhos que ainda moram no mesmo domicílio das mães e foi verificado que em média, no Brasil, este porcentual é de $92 \%$ para mulheres de 30 anos, $87 \%$ para mulheres de 40 anos e $63 \%$ para mulheres de 50 anos. 
da renda dos filhos teria o efeito de reduzir a educação destes, distorcendo a motivação da inclusão da renda familiar citada em Leibowitz (1974). Da mesma forma, a renda da mãe também será excluída, pois representa um custo de oportunidade de ela ter filhos, isto é, mulheres com uma maior renda no mercado de trabalho provavelmente alocam menos tempo na criação dos filhos, contrariando a proposta de inclusão da renda familiar com o sentido de obter uma variável proxy para o investimento financeiro na educação dos filhos.

Leibowitz (1974) considerou a escolaridade da mãe importante para prever a formação de capital humano inerente ao indivíduo também por que esta constitui uma variável proxy para o investimento familiar não financeiro na educação dos filhos. Ao contrário, a escolaridade do pai tem pouco efeito sobre o estoque de capital humano inerente aos filhos, mas é uma proxy para o investimento familiar, em termos de alocação de renda. Portanto, a escolaridade das mães será incluída neste trabalho com o objetivo de obter uma medida de qualidade de tempo gasto no cuidado e educação dos filhos, ao passo que a renda do pai será incluída como uma medida de investimento financeiro.

A inclusão da variável cor ou raça da mãe representa o fato de que algumas instituições religiosas possuem um caráter que se aproxima da própria cultura de origem étnica dos seus adeptos. As religiões afro-brasileiras possuem elevado porcentual de negros; na judaica, os indivíduos são majoritariamente brancos; e os budistas são representados em quase 33\%, em 1991, por indivíduos de cor amarela, provavelmente japoneses e seus descendentes. Por este motivo, resolveu-se incluir esta variável para que se possa verificar o efeito da identidade religião-cultura apresentada por alguns grupos religiosos e também com um intuito de obter uma contribuição líquida da opção religiosa para a escolaridade dos filhos.

Como o povoamento foi realizado de forma gradual pelas regiões do País, e a região Nordeste foi a primeira região colonizada, povos como os negros africanos deixaram nesta região fortes traços de sua cultura e religião. Da mesma forma, no Estado de São Paulo, especialmente no município de São Paulo, existe a maior concentração de japoneses do País. Deve haver, portan- 
to, uma correlação alta entre a região habitada pelos japoneses e a tradição cultural e espiritual do grupo budista, justificando a inclusão da variável que identifica as regiões metropolitanas.

Pesquisas sobre a instabilidade do casamento classificam os filhos como uma forma de investimento específico do casamento. Testes empíricos mostram que a probabilidade de dissolução deste é menor com a presença de crianças na família. O casamento, sob este aspecto, deveria aumentar a demanda pela quantidade ou elevar o investimento em capital humano dos filhos. (BECKER, LANDES \& MICHAEL, 1977). A variável que identifica mulheres casadas tem por objetivo identificar os efeitos que o casamento pode ter sobre a instituição familiar. O casamento pode estar associado a um efeito-renda, em que o orçamento da família biparental apresenta-se maior do que o da família monoparental em termos per capita. As transferências de renda ou pensões esperadas, freqüentemente por parte dos pais, após um divórcio ou separação, podem não ser equivalentes à renda destinada à família antes da separação, assim como espera-se que casamentos ocorridos inclusive no religioso estejam associados a uma maior duração da união por conformidade às regras da instituição religiosa, enquanto casamentos informais - união consensual - e realizados apenas no civil podem estar associados a uma segunda união. Portanto, um efeito-renda positivo proporcionado pelo casamento deve aumentar o investimento em educação dos filhos, elevando a acumulação de capital humano na família.

O número de irmãos é importante, pois tenta controlar o efeito que opção religiosa tem de influenciar a escolha das famílias pelo número de filhos e, assim, afetar o investimento na qualidade dos mesmos. Tal relacionamento entre fecundidade e opção religiosa foi enfatizado pela Figura 10.

Por último, a variável idade do filho mais velho tem como objetivo captar o nível de escolaridade considerado normal conforme a idade que ele possui. No presente estudo, optou-se por filhos que estejam com idade entre 7 e 22 anos, ao contrário de muitos trabalhos que definem como idade escolar a faixa entre 7 e 18. O motivo dessa escolha é justamente obter a escolaridade do filho mais velho das mulheres de 40 a 45 anos, de onde se espera maior acumulação de capital humano. Procura-se captar a escolaridade daqueles 
que freqüentaram não só o ensino primário e secundário, mas também o ensino superior.

\section{II.3 Os Determinantes do Nivel de Escolaridade dos Filhos}

A regressão 1 (Tabela 4) inclui todas as variáveis previstas no modelo mostrado anteriormente, e apresentou correlações parciais significativas e positivas entre os anos de escolaridade da mãe e renda familiar per capita, e a variável dependente - escolaridade dos filhos. Esse efeito mostra que quanto maior o investimento - tanto em termos financeiros quanto na forma de alocação de tempo dedicado aos filhos -, maior será o resultado na educação destes.

Outras correlações significativas são relacionadas à área geográfica. Os coeficientes estimados apontam que as famílias morando na região Sul do País investem mais em educação dos filhos do que nas regiões Sudeste e CentroOeste e, por fim, Norte e Nordeste. Mesmo controlados os fatores socioeconômicos, como renda familiar, escolaridade, status conjugal e cor ou raça da mãe, os níveis de escolaridade no Sul se mantêm superiores. Este resultado pode ser explicado pelos diferenciais de qualidade do ensino na região. A variável que informa se o indivíduo mora em uma região metropolitana também é significativa e correlacionada positivamente com a escolaridade dos filhos.

A taxa de fecundidade é negativamente correlacionada com a escolaridade das mães. Como o número de irmãos está controlado na regressão da escolaridade dos filhos, o coeficiente desta variável mostrou-se relativamente baixo (em torno de $0,9 \%$ ). Por outro lado, os coeficientes da variável status conjugal denotam que mulheres casadas no religioso e civil contribuem mais para a escolaridade dos filhos do que as mulheres solteiras, separadas ou divorciadas e casadas apenas em união civil ou consensual.

Os coeficientes obtidos na regressão demonstram que mães de cor amarela possuem, em média, filhos com maior escolaridade do que mães de cor branca (10\%). Essas, por sua vez, apresentaram coeficiente positivo e cerca de $22 \%$ maior que o grau de escolaridade dos filhos de mães negras ou par- 
das. Verifica-se que há grande influência da variável cor para a escolaridade dos filhos. Este resultado pode ser indicativo de diferenças culturais ou sociais não captadas pelos dados empregados.

As variáveis para cada instituição religiosa estão expressas em relação à religião católica. Assim sendo, os coeficientes da regressão 1, Tabela 4, medem, para cada opção religiosa, a variação (em anos de estudo) da escolaridade dos filhos comparada à das mulheres católicas. Os resultados mostram coeficientes significativos no nível de 5\%, exceto para as mães budistas. Quando se controla por região metropolitana, nenhum coeficiente significativo pode ser verificado em relação ao grupo de mulheres católicas.

Verificou-se, por meio dos demais coeficientes, a existência de um efeito líquido da opção religiosa das mães sobre a escolaridade dos filhos, isto é, considerando as variações apresentadas pelos demais parâmetros das variáveis socioeconômicas. Os filhos das mulheres pertencentes à instituição judaica apresentaram, em média, um diferencial de escolaridade $26 \%$ superior aos filhos das mulheres católicas. Em seguida, filhos de kardecistas mostram um diferencial de $11 \%$ e filhos de protestantes tradicionais com 10,2\% ainda acima da escolaridade dos filhos das católicas.

Por outro lado, a escolaridade dos filhos de mães pentecostais, afro-brasileiras e daqueles cujas mães declararam não possuir religião apresentaram resultados inferiores à escolaridade dos filhos das católicas. Estes resultados mostram que, mesmo controladas as características que se associam fortemente a este grupo, como população com baixo nível de renda e de escolaridade, elevada proporção de mulheres casadas em união consensual e altas taxas de fecundidade, a opção religiosa pentecostal tem um efeito líquido negativo para a escolaridade dos filhos. A opção religiosa pentecostal pode conter algo intrínseco em suas normas ou crenças que levam as famílias a acumular menos capital humano do que a tendência observada nas demais denominações. 


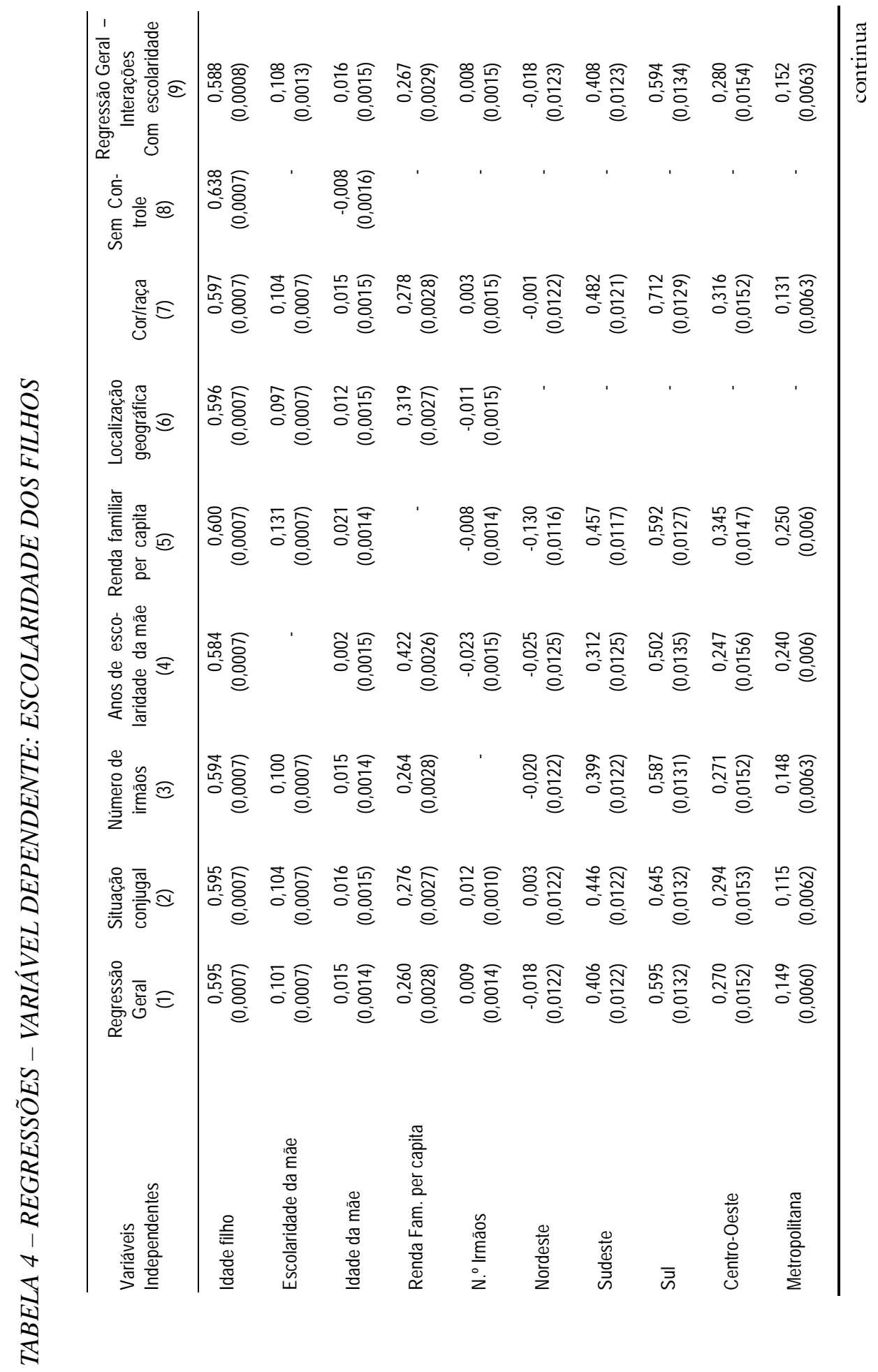

Est. econ., São Paulo, 34(3): 453-486, jul-set 2004 


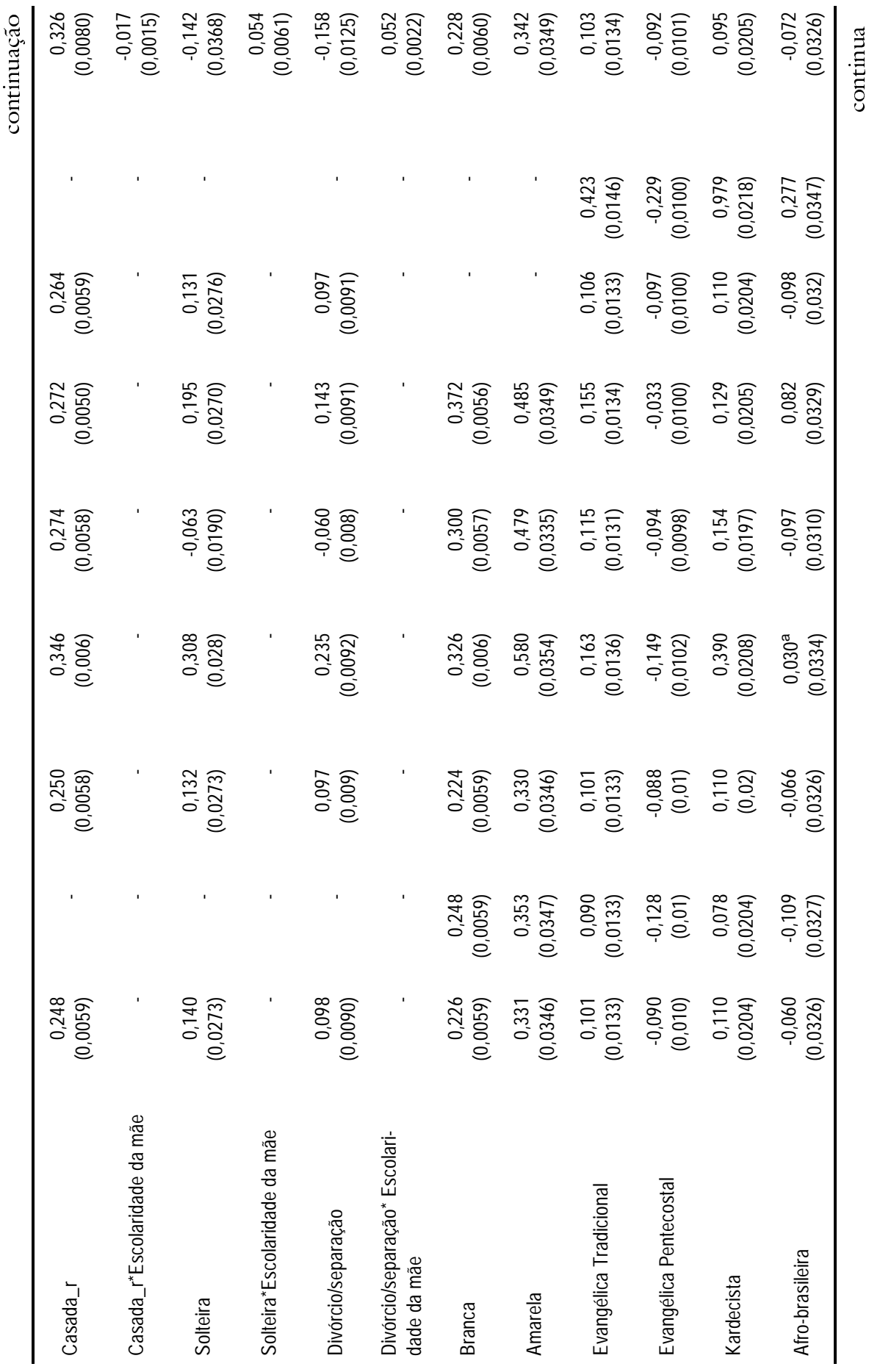


胥

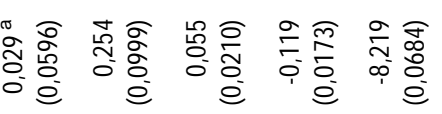

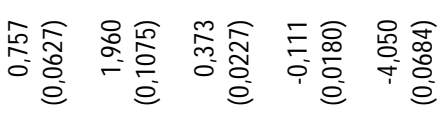

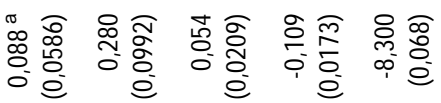

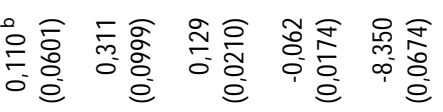

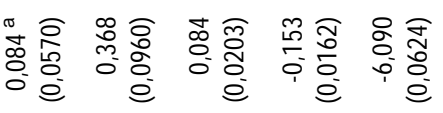

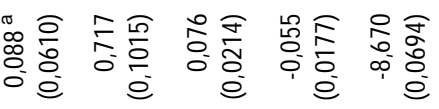

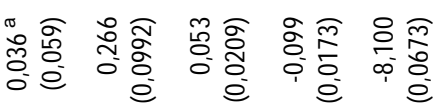

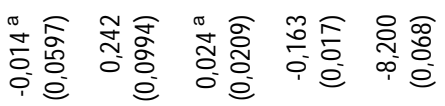

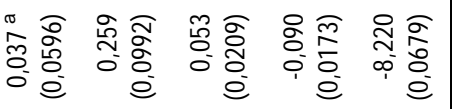

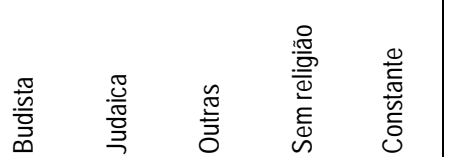

華恖

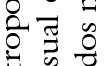

氙 0

خ

इ

$\approx \equiv$

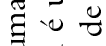

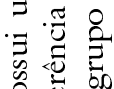

¿ิ ये

$\because \pm 0$

芵艺

‡

인

$\stackrel{\Xi}{\Xi} \stackrel{\circ}{\Xi}$

i

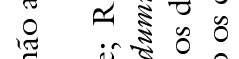

‡

of 0 党

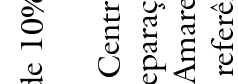

च $0 \frac{0}{0} \pi$

ज.

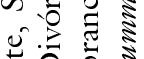

की 0 व

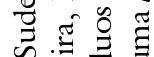

胥

एक

过 $\cong . \Xi$

ठี $\widetilde{\pi}$

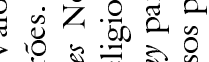

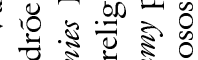

น

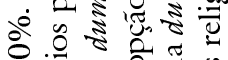

궁 क

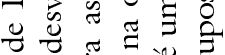

ए 0 है:

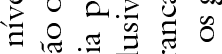

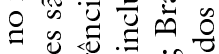

\& 40 ए

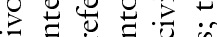

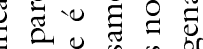

पै

क

क ज $=$ त

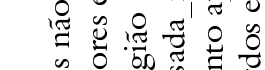

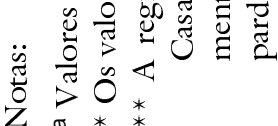


Além da Regressão (1), a Tabela 4 apresenta mais 6 regressóes com o objetivo de explorar algumas correlações entre as variáveis socioeconômicas, cor ou raça e localização geográfica da família e as relacionadas à opção religiosa da mãe, isolando-se uma variável por vez. A regressão (8) foi realizada sem o controle por estas 6 variáveis e a regressão (9) foi estimada incluindo, além das variáveis apresentadas na regressão (1), interações entre escolaridade e dummies indicadoras de situação conjugal.

O resultado mais importante aponta uma elevada correlação entre a escolaridade da mãe e opção religiosa. Os coeficientes da Regressão (4) mostram que, quando isolada a variável escolaridade da mãe, há uma significativa alteração dos coeficientes, quando comparados aos da regressão (1). Renda familiar per capita apresentou a segunda maior correlação com opção religiosa. Em seguida, localização geográfica e cor ou raça mostram correlações maiores que situação conjugal e número de irmãos.

Quando isoladas as variáveis de localização geográfica - Regressão (6) -, o coeficiente de budistas passa a ser significativo no nível de $10 \%$, podendo confirmar a hipótese estabelecida de que alguns grupos podem estar refletindo a concentração em determinadas macrorregiões ou, como é o caso de dos budistas, existe forte concentração na região metropolitana de São Paulo, região que apresenta elevado diferencial de escolaridade relativamente às demais regiões do País.

Pela Regressão (7) verifica-se que os diferenciais de escolaridade da maior parte destas religiões em relação à católica são alterados em relação à regressão (1) quando isolada a variável cor ou raça. Isto produz efeitos sobre o aumento da escolaridade dos filhos de evangélicas tradicionais em relação às católicas e piora da escolaridade dos filhos de evangélicas pentecostais em relação ao mesmo grupo. Tal resultado é explicado pela composição dos grupos religiosos. Como o porcentual de brancos na composição do grupo das evangélicas tradicionais é maior do que o das católicas, enquanto o porcentual de negros e pardos é maior nas pentecostais do que o apresentado entre as católicas, ao se retirar a variável cor ou raça da análise, obtém-se que grupos com um porcentual elevado de brancos têm a escolaridade dos filhos aumentada. 
A Regressão (3) retira a variável número de irmãos e não se observa grande variação dos coeficientes em relação à Regressão (1). Entretanto, a Regressão (2) mostra que, quando retiradas as variáveis referentes à situação conjugal, os coeficientes variam relativamente pouco, mas é curioso observar que o sentido da alteração reflete principalmente o fato de que os grupos que possuem porcentual menor de mulheres casadas na opção religiosa ou civil e religiosa apresentaram uma queda da escolaridade dos filhos em relação ao grupo das católicas. Esse é o caso das pentecostais e do grupo sem opção religiosa, que tiveram uma perda ainda maior em relação às católicas, o que mostra que a opção de casamento, inclusive no religioso, pode elevar, ainda que em níveis reduzidos, a educação dos filhos.

No entanto, os piores efeitos são aqueles verificados para as mães casadas em união consensual ou apenas no civil. Cabe ressaltar que este resultado é inferior inclusive ao obtido pelas mães solteiras e mães divorciadas. Isso é um tanto surpreendente, pois esperava-se que os resultados de famílias biparentais fossem superiores, tanto em virtude dos investimentos financeiros como em decorrência de a variável tempo dedicado pelos pais à educação dos filhos serem provavelmente maiores que os da família monoparental.

Note, contudo, que o efeito da escolaridade deve ser ainda mais forte em grupos de mulheres solteiras, divorciadas ou separadas, já que, ainda no começo dos anos 90, a incidência de divórcios ou separações foi maior entre as mulheres com maior nível de instrução. Por este motivo, a Regressão (9) foi estimada incluindo interações entre escolaridade das mães e variáveis que indicam sua situação conjugal. Pelos coeficientes dessa última regressão, confirma-se a predição de que a acumulação de capital humano foi curiosamente maior em famílias monoparentais (mulheres solteiras, divorciadas ou separadas) devido a um efeito superior da escolaridade nesses grupos. Isso pode ser visto pelos coeficientes das interações entre escolaridade e situação conjugal, que mostram valores significativos a $1 \%$ e positivos para as mulheres solteiras, divorciadas ou separadas, enquanto o valor é negativo e significativo a $1 \%$ para as casadas na opção civil e religiosa, mostrando que estas últimas perdem em relação ao grupo das casadas em união consensual (ou apenas civil) à medida que cresce a escolaridade. 
A Regressão (9) também mostra que os coeficientes de religião são praticamente robustos quando comparados aos da Regressão (1). A Tabela 5 resume os efeitos da opção religiosa das mães sobre a acumulação de capital humano dos filhos (em termos de escolaridade).

TABELA 5 - OPÇÃO RELIGIOSA DAS MÃES E EFEITOS SOBRE A ESCOLARIDADE DOS FILHOS

\begin{tabular}{lc}
\hline Opção Religiosa & $\begin{array}{c}\text { Porcentual de Ganho/Perda de Escolaridade } \\
\text { em Relação à Opção Católica }\end{array}$ \\
\hline Judaica & 25,4 \\
Evangélica Tradicional & 10,3 \\
Kardecista & 9,5 \\
Outras & 5,5 \\
Budista & $2,9^{a}$ \\
Afro-brasileira & $-7,2$ \\
Evangélica Pentecostal & $-9,2$ \\
Sem religião & $-11,9$ \\
\hline
\end{tabular}

a Valor não significativo no nível de $10 \%$.

A tabela acima classifica as opçóes religiosas de acordo com o ganho observado em relação à católica. Tais resultados, baseados na Regressão (9), confirmam que a religião afeta a acumulação de capital humano na família observado via escolaridade dos filhos - independentemente de fatores socioeconômicos que poderiam explicar os efeitos obtidos em diferentes grupos religiosos.

Em outras palavras, controlados por renda familiar, cor ou raça, situação conjugal, taxa de fecundidade e pela escolaridade das mães, os filhos de mulheres judaicas possuem uma escolaridade em média 25,4\% superior à dos filhos das mulheres católicas, ou seja, para cada 4 anos de escolaridade dos filhos de adeptas ao catolicismo, os filhos de adeptas a instituição judaica têm 1 ano a mais de escolaridade. Por sua vez, o pior resultado foi verifica- 
do entre as pessoas que não possuem religião. Para estas, a cada 9 anos de escolaridade dos filhos das católicas, os filhos de pessoas sem opção religiosa declarada acumulam 1 ano a menos de escolaridade.

\section{CONCLUSÕES}

Este estudo espera dar uma contribuição para o entendimento das conseqüências econômicas da opção religiosa no Brasil. Destaca-se o grande crescimento do pentecostalismo entre 1980 e 1991, quando o número de adeptos praticamente dobrou, sendo que o número de sacerdotes pentecostais cresceu em termos absolutos na mesma proporção, mantendo a razão de 12 para cada 10 mil fiéis. No mesmo período as instituições religiosas tradicionais mantiveram praticamente constante o número absoluto de sacerdotes. Empregando-se o questionário especial da PNAD 1988, pode-se constatar que o crescimento do pentecostalismo está também associado a um maior engajamento nas atividades religiosas, medido pela freqüência do indivíduo nos cultos da instituição, semelhante aos protestantes tradicionais, mas superior às demais instituições. A diversidade de instituições religiosas no País apresenta um duplo padrão no grau de coerência da opção religiosa - indicado pelo porcentual de participação exclusiva na instituição. De um lado, protestantes e católicos com elevado grau de coerência, de outro, os kardecistas e adeptos às afro-brasileiras, com grau relativamente baixo, sendo que isso se deve, em grande parte, ao fato de muitos deles terem o catolicismo como opção religiosa secundária, tornando evidente um aspecto de transição dos conversos da instituição católica para estas instituições. As evidências empíricas reunidas reproduzem alguns fatos estilizados encontrados pelos trabalhos em Economia da Religião (IANNACCONE 1998) e trazem também comportamentos específicos que merecem estudos adicionais.

Os efeitos econômicos da opção religiosa podem se manifestar de várias formas. Uma delas é sobre a acumulação de capital humano. Este estudo teve como objetivo central testar a presença de efeitos da adesão religiosa das mulheres sobre a escolaridade dos filhos. Para uma amostra de mães entre 40 e 45 anos de idade, extraída do Censo Demográfico de 1991, considerando as variações existentes entre os diferentes grupos religiosos quanto à 
cor ou raça, escolaridade, renda, situação conjugal, número de irmãos e localização geográfica, identificou-se a presença de um efeito líquido da opção religiosa sobre a escolaridade dos filhos.

Obteve-se que os filhos das mulheres pertencentes à instituição judaica apresentaram, em média, um diferencial de escolaridade $25,4 \%$ superior aos filhos das mulheres católicas. Em seguida, filhos de protestantes tradicionais mostram um diferencial de 10,3\% e filhos de kardecistas de 9,5\% acima da escolaridade dos filhos das católicas. Por outro lado, a escolaridade dos filhos de mães pentecostais, afro-brasileiras e daqueles cujas mães declararam não possuir religião apresentaram resultados inferiores à escolaridade dos filhos das católicas.

Estes resultados mostram que, mesmo controladas as características que se associam fortemente aos adeptos das pentecostais, das afro-brasileiras e às pessoas que não possuem religião - como população com baixo nível de renda e de escolaridade, elevada proporção de mulheres casadas em união consensual e alta taxa de fecundidade -, tais opções têm um efeito líquido negativo para a escolaridade dos filhos.

Evidentemente, este trabalho não esgota a análise dos diferenciais de escolaridade encontrados entre diferentes opções religiosas. Trabalhos futuros poderiam testar a robustez de tais resultados usando informaçóes mais recentes dos censos demográficos, já que as religiões tradicionais, como este trabalho mostra, vêm perdendo espaço para as novas denominaçôes religiosas.

Uma análise preliminar a partir de tabulações recentes do Censo de 2000 mostra que o número de evangélicos e de pessoas sem opção religiosa praticamente dobrou em relação ao ano de 1991, enquanto que o crescimento do número de adeptos ao catolicismo nem mesmo acompanhou o crescimento populacional. Note-se, portanto, que este movimento observado na década de 90 replica aquele que foi mostrado aqui para os anos 80 . Nesse sentido, espera-se, no ano de 2000, um resultado similar para a relação entre a opção religiosa das mães e escolaridade dos filhos encontrada no presente estudo. 


\section{REFERÊNCIAS BIBLIOGRÁFICAS}

AZZI, C.; EHRENBERG. R. Household allocation of time and church attendance. Joumal of Political Economy, Chicago, v. 83, n. 1, p. 27$56,1975$.

BECKER G. S.; LANDES E. M.; MICHAEL R. T. An economic analysis of marital instability. Journal of Political Economy, Chicago, v. 85, n. 6, p. 1141-1187, 1977.

BECKER, G. S.; LEWIS G. H. On the interaction between the quantity and quality of children. Journal of Political Economy, Chicago, v. 81, p. 279-288, 1973.

CAMARGO, C. P. F. Kardecismo e umbanda: uma interpretação sociológica. São Paulo: Pioneira, 1961.

EHRENBERG. R. Household allocation of time and religiosity: replication and extension. Journal of Political Economy, Chicago, v. 85, n. 2, p. $415-423,1977$.

FEATHERMAN, D. L. The socioeconomic achievement of white religioethnic subgroups: social and psychological explanations. American Sociological Review, v. 36, p. 207-222, abril 1971.

FINKE, R. The consequences of religious competition. In: YOUNG, Lawrence (org.), Rational choice theory and religion. Nova Iorque: Routledge, 1997.

IANNACCONE, L. Introduction to the economics of religion. Journal of Economic Literature, v. 36, n. 3, p. 1465-1496, setembro 1998.

LEIBOWITZ, A .Home investments in children. Journal of Political Econo$m y$, v. 82, n. 2, p. 111-131, março/abril 1974.

LENSKI, G. E. Social correlates of religious interest. American Sociological Review, v. 18, p. 533-544, outubro 1953.

MACHADO, M. D. C. Carismáticos e pentecostais: adesão religiosa na esfera familiar 1996. Tese (Doutorado). São Paulo: ANPOCS.

RAZIN, A.; SADKA, E. Population economics. Massachusetts: The MIT Press, 1995.

STARK R.; IANNACCONE, L.; FINKE, R. Religion, science and rationality. American Economic Review, v. 86, n. 2, p. 433-437, 1996.

TODARO, M. P. Economic development in the third world. $4^{\mathrm{a}}$ ed. Longman, 1988.

WEBER, M. A ética protestante e o espirito do capitalismo. $11^{\mathrm{a}}$ ed. São Paulo: Pioneira, 1996.

YOUNG, L. Rational choice theory and religion. Nova Iorque: Routledge, 1997.

Os autores agradecem ao Professor Reynaldo Fernandes, por várias contribuições, e a um parecerista anônimo, que indicou a correta interpretação dos resultados da interação entre escolaridade e estado civil das mães.

(fanuatti@usp.br)

(rnarita@econ.puc-rio.br)

(Recebido em janeiro de 2002. Aceito para publicação em abril de 2004). 